\title{
Application of Barkhausen Noise for Analysis of Surface Integrity after Hard Turning
}

Prof. Dr. Ing. Miroslav Neslušan ${ }^{1}$, Ing. Martin Rosipal ${ }^{1}$, Ing. Kamil Kolařík, PhD. ${ }^{2}$, Ing. Vladislav Ochodek ${ }^{3}$, ${ }^{1}$ Department of Machining and Manufacturing Engineering, Faculty of Mechanical Engineering, University of Žilina, Univerzitná 1, 010 26, Slovak Republic, miroslav.neslusan@fstroj.utc.sk,

${ }^{2}$ Department of Solid State Engineering, Faculty of Nuclear Sciences and Physical Engineering, CTU in Prague; Trojanova 13, 12000 Prague 2, Czech Republic; kamil.kolarik@email.cz,

${ }^{3}$ Department of Solid State Engineering, Faculty of Mechanical Engineering, VŠB TU in Ostrava, 17. listopadu 15,

708 33, Czech Republic; vladislav.ochodek@vsb.cz

Introduction into problems - This paper deals with the application of Barkhausen noise for investigation of residual stresses after hard turning. The results illustrate the differences in the stress distribution after hard turning and grinding. The analysis of the stress and structure state shows that the conventional evaluation of Barkhausen noise fails and monitoring of surface integrity will require a subsequent modified approach. The main reason for it is a more complicated relationship between stresses, surface hardness and structure. And so the modified approach is described for monitoring surface integrity after hard turning operations. This modification is based on the biaxial stress with the high correlation to the tool wear. The main idea is based on the non proportional increase of stress in the different directions.

Keywords: residual stress, hard turning, Barkhausen noise

\section{Acknowledgment}

This project is solved under the financial support of VEGA agency (project n.1/0223/11) and also project TA02011031 (Technological Agency of Czech republic).

\section{References}

[1] KARPUCHEWSKI, B. (2002). Introduction to micromagnetic techniques, ICBM1 report, Hanover 2002.

[2] ALTPETER, I., THEINER, I. W., BECKER, W. R. (1981). Eigenspannungsmessung an stal deer Güte 22 NiMoCr 37 mit magnetischen und magnetoelastischen Prüfverfahren, 4th Intern. Conf. on NDE in Nuclear Industry, Lindau1981.

[3] MATSUMOTO, Y., HASHIMOTO, F., LAHOTI, G. (1999). "Surface Integrity Generated by Precision Hard Turning”, in: CIRP Annals 48/1/1999, p. 59-82.

[4] BRANDT, D. (1995). Randzonenbeeinflussung beim Hartdrehen, Dr.-Ing. Dissertation, Universität-Hannover, 1995.

[5] HASHIMOTO, F., GUO, Y. B., WAREN, A. W. (2006). Surface Integrity Difference between Hard Turned and Ground Surfaces and its Impact on Fatigue Life, in: CIRP Annals 55/1/2006, p. 81 - 84.

[6] WANG, J. Y., LIU, C. R. (1999) The effect of Tool Flank Wear on the Heat Transfer, Thermal Damage and Cutting Mechanics in Finishing Hard Turning, in: CIRP Annals, 48/1/1999, p. 53 - 56.

[7] KUNDRÁK, J. (2011). Alternative machining procedures of hardened steels, in: Manufacturing Technology, XI/2011, ISSN 1213-2489, p. 32 - 39.

[8] NOVÁK, M. (2011). Surface quality of hardened steels after grinding, in: Manufacturing Technology, XI/2011, ISSN 1213-2489, p. $55-59$.

[9] JERSÁK, J., et. all, (2010) Surface integrity of hardened bearing steel after milling, in: Manufacturing Technology, X/2010, ISSN 1213-2489, p. $80-87$. 